\title{
Unemployment Insurance, Payroll Taxes and Employment
}

\author{
by Erling Steigum, Jr. *
}

The topic of unemployment insurance raises a wide range of interesting and important questions, both from the viewpoint of the economic theory of insurance, and from a more practical, policy-oriented point of view. In his excellent lecture Edmond Malinvaud has given a well balanced survey of those questions and issues.

Looking at the unemployment situation in the OECD-area, one is struck by the large dispersion of unemployment rates across nations, ranging from below 3 per cent in countries like Switzerland, Japan and Sweden to about 17 per cent in Holland. In large European countries like France, Western Germany and United Kingdom the rate of unemployment has for some time been around 10 per cent (in the U.K. even considerably higher), which is far above what could reasonably be labelled "the natural rate of unemployment".

Before one can answer questions such as those related to the "optimality" of unemployment insurance systems, and the best way of financing them, one needs to know the cause or causes of unemployment. Although considerable progress has been made in this branch of economic theory in the last decade - a development in which Edmond Malinvaud has played a major role ${ }^{1}$ - a general theory of unemployment has still not materialized. Still worse, there appears to be considerable disagreement among economists about the fundamental causes of unemployment and the means by which excessive unemployment can be eliminated.

This explains, I think, why a general unified approach to the questions of the role of unemployment insurance in economic stabilization, redistribution policy and resource allocation is not feasible. When discussing economic stabilization, Malinvaud assumes that the cause of the unemployment is price and wage rigidities which give rise to market coordination failures. In the section where aspects of resource allocation are discussed, however, the unemployment appears to be of the "frictional" type. In the older public finance literature, when dealing with similar questions, it was customary to assume that the government always pursued an appropriate stabilization policy (which was synony-

* Professor, Norwegian School of Economics and Business Administration, Bergen.

See Malinvaud [1977, 1980]. 
mous with aggregate demand policy) which eliminated all involuntary unemployment due to the business cycle. Considering the supply shocks and the failure of stabilization policy to cope with the stagflation in the last decade, this assumption appears more questionable now than it did in the 50 -ies and 60 -ies.

If one assumes that a perfect stabilization policy is not feasible, or worse, does not exist, then the unemployment insurance system could matter a great deal for the macroeconomic performance of the economy in question. In particular, there might exist a conflict between microeconomic and macroeconomic considerations. As we know there exist sound microeconomic reasons for introducing "experience ratings" in order to let the firms and industries which are most likely to generate unemployment pay correspondingly high contribution rates. Such an insurance system should work well if unemployment is mainly frictional. If, however, the rate of unemployment becomes abnormally high, for example because of a particularly severe macroeconomic disturbance, a rule linking the unemployment contribution rate to past benefit payments may have undesirable effects on the level of employment in addition to those caused by the disturbance itself.

In what follows, these dynamic aspects will be given a little further consideration. Suppose the contribution rate in period $t\left(\tau_{t}\right)$, which, of course, acts as a payroll tax, adjusts according to the following equation

$$
\tau_{t}=\Theta \tau_{t-1}+(1-\Theta) \frac{B_{t-1}}{W_{t-1} L_{t-1}},
$$

where $B_{t-1}$ is last period's payment of unemployment benefits, $W_{t-1}$ is the nominal (average) wage rate, $L_{t-1}$ is aggregate employment in period $t-1$, and $\Theta$ is a parameter, $0 \leqslant \Theta \leqslant 1$. If $\Theta=1$, the payroll tax is constant, independent of past payments of unemployment benefits, i.e. changes over time in $B_{t}$ are accommodated by the public sector budget. If $\Theta<1$, the average contribution rate increases over time if the rate of unemployment increases.

In order to examine some dynamic macroeconomic implications of different $\Theta$ 's, I have included equation (1) in a small macroeconomic simulation model of a closed economy.

The model is a "disequilibrium" model with short-run price and real wage stickiness, and a flexible rate of interest clearing the bond market (or if one likes, the "money market") in each period. Output $\left(Y_{t}\right)$ is produced by competitive firms according to an aggregate Cobb-Douglas production function

$$
Y_{i}=A L_{t}^{\alpha} K_{t-1}^{1-\alpha} \text {, }
$$

where $K_{t-1}$ is fixed capital at the end of period $t-1$ (the beginning of period $t$ ). Labor $\left(L_{t}\right)$ is a variable input, the supply of which is constant in all periods. The notional supply of output and the notional demand for labor, given $K_{t-1}$, follow from profit maximization in the familiar way. In addition we take into account sales constraints and labor shortage constraints whenever appropriate. The demand for investment $\left(I_{t}^{d}\right)$ is governed by a "flexible accelerator" mechanism

$$
I_{t}^{d}=\lambda\left(\mathrm{d} K_{t}^{\bullet}-K_{t-1}\right)+\delta K_{t-1}, \quad(1>\lambda>0),
$$


where the last term in (3) is the flow of replacement investment, and desired capital $\left(K_{t}^{\bullet}\right)$ is derived from the conditions of long-run cost minimization for a given planned output level, $Y_{i}^{P}$.

We assume $Y_{t}^{P}$ to be entirely influenced by the current level of aggregate demand when excess supply of output prevails (Keynesian unemployment), and only by business profitability when there exists excess demand for output (classical unemployment or repressed inflation).

Consumers' demand for goods $\left(C_{t}\right)$ and real money balances $\left(m_{t}\right)$ is generated from maximization of the following intertemporal utility function

$$
U=\sum_{t=1}^{\infty}\left(\frac{1}{1+\rho}\right)^{t-1}\left[\beta \log \left(C_{t}\right)+(1-\beta) \log \left(m_{t}\right)\right]
$$

subject to a perceived wealth constraint

$$
\sum_{t=1}^{\infty}\left(\frac{1}{1+r}\right)^{t-1}\left[C_{t}+m_{t}\right]=\Omega_{1} \text {. }
$$

For the sake of simplicity, we abstract from expectations of inflation. Hence, $r$ is both the nominal and the real rate of interest. Perceived real wealth in period $t\left(\Omega_{t}\right)$ includes initial real stocks of money and government bonds as well as discounted future expected private (after-tax) incomes (labor and capital incomes). From (4) and (5) we obtain the notional demands for consumption and real money balances :

$$
\begin{aligned}
& C=\frac{\beta \rho}{1+\rho} \Omega_{t} \\
& m_{t}=\frac{(1-\beta)\left(1+r_{t}\right)}{\beta r_{t}} C_{t}
\end{aligned}
$$

In our numerical experiments, the consumption function (6) has been slightly modified to take into account a positive redistribution effect from unemployment benefits. Whenever excess demand for goods, private consumption and investment are each reduced in equal proportions to total excess demand. The real demand for output by the government sector $(G)$ is exogenous, and there is a linear tax function. The nominal money supply is constant over time, i.e. any public deficit or surplus is financed by public borrowing or lending.

Expectations are adaptive. If $x_{t}^{\bullet}$ is the expectation of the future value of the variable $x$ at time $t$, then

$$
x_{i}^{\bullet}=\gamma x_{i-1}^{\bullet}+(1-\gamma) x_{t}, \quad(0<\gamma<1) .
$$

Given its history, the model generates in each period a short-run temporary equilibrium. This short-run equilibrium changes over time due to the dynamic equations in the model. In addition to the dynamics of investment, wealth accumulation, and expectation modifications, real wages and the nominal price level change over time in response to excess demands and supplies in the markets for labor and output. In the real wage equation, we have also included a link between business profitability and next period's real wage, i.e. high profitability affects real wages positively.

Since this dynamic model is fairly complicated, we have resorted to numerical simulations. Details are given in the Appendix. Starting from a Walrasian stationary 
equilibrium, we first exposed the model to a deflationary demand shock (by reducing the rate of time preference $(\rho)$ by 10 per cent). The resulting evolution of the rate of unemployment is displayed in Figure 1.

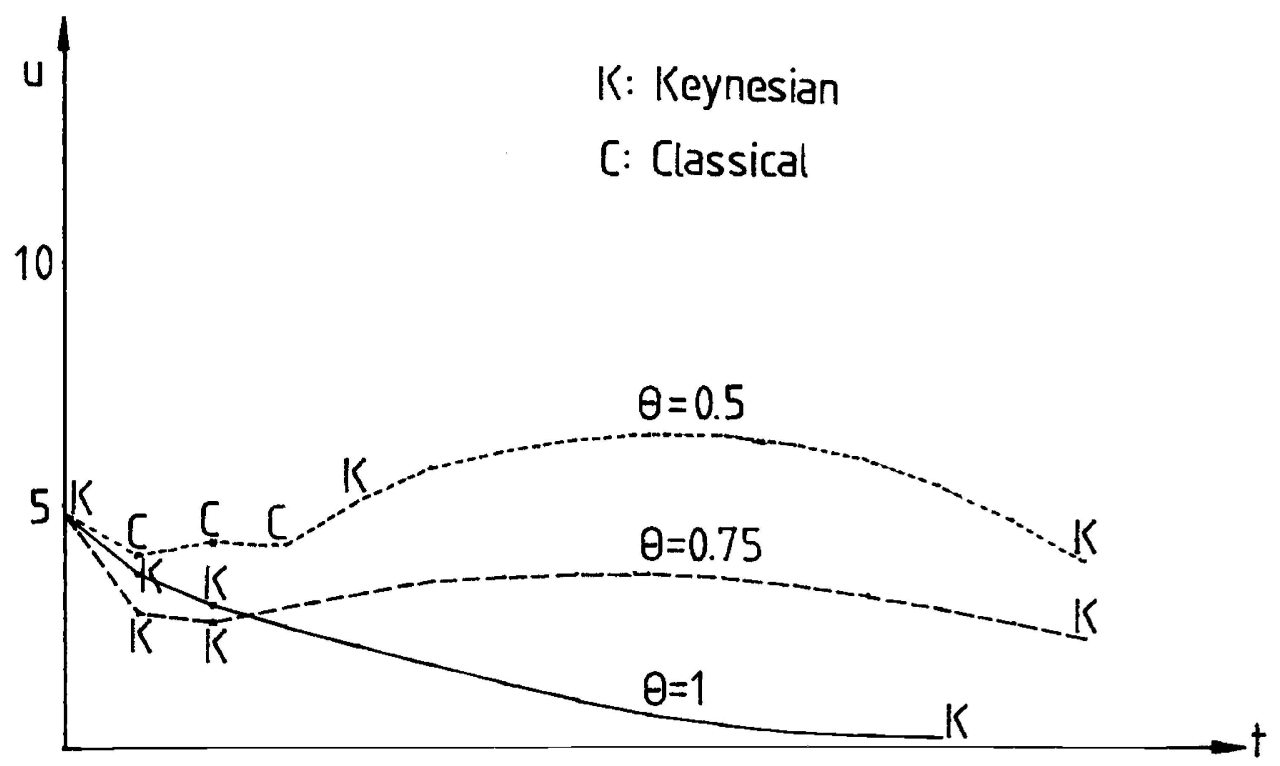

Fig. 1. Demand disturbance

If the unemployment benefits are entirely financed by public borrowing $(\Theta=1)$, the rate of unemployment (which is of the "Keynesian" type due to insufficient aggregate demand), is seen to decrease over time, starting at 4.8 per cent in period 1 . The rate of interest will decrease in period 1 , and the excess supply of goods will exert a downwards pressure on the nominal price level. There will be a continuous, but decreasing government budget deficit.

If $\Theta=0.75$, the payroll tax rate will gradually increase over time and then decrease again in the long run. Although the cost of labor increases, the unemployment will still be Keynesian all the time. In period 2 and 3 it will be lower than in the previous case because the demand for investment is temporarily higher. However, from period 4 and onwards, the rate of unemployment increases and stays above three per cent for a while before it eventually approaches zero. This prolongment of the recession is caused by the automatic fiscal policy restraint which depresses private consumption demand compared with the previous case.

Lowering $\Theta$ to 0.5 is seen to involve an intermezzo with classical unemployment (the real wage exceeding its market clearing level, coupled with excess demand for output). The recession becomes deeper and lasts longer. This means a loss of income tax revenues which increases the public borrowing requirement beyond that of the two previous cases even though the intention might have been exactly the opposite. This has some resemblance to a "Laffer curve" effect. 
So far we have examined the effect on unemployment of a demand disturbance when no active stabilization policy is pursued. If, on the other hand, the supply of money is increased permanently in period 1 (by 8 per cent, say), the rate of unemployment falls to 1.4 per cent in period 1 , followed by repressed inflation in period $2(\Theta=1)$. In this model monetary policy stimulates the demand for investment through a fall in the rate of interest in the familiar way.

Suppose next, again starting from the stationary Walrasian equilibrium, that the economy is exposed to the following "supply shock": The efficiency parameter $A$ in the production function drops by 2.5 per cent. The resulting effect on the rate of unemployment over time is illustrated in Figure 2. In the case of no increase in the payroll tax rate $(\Theta=1)$, the unemployment is first classical and then becomes Keynesian. The increase in the rate of unemployment in period 5 occurs because the inflation triggered off by the supply shock reduces the real money supply and therefore pushes up the rate of interest. (The nominal supply of money is constant throughout) ${ }^{2}$.

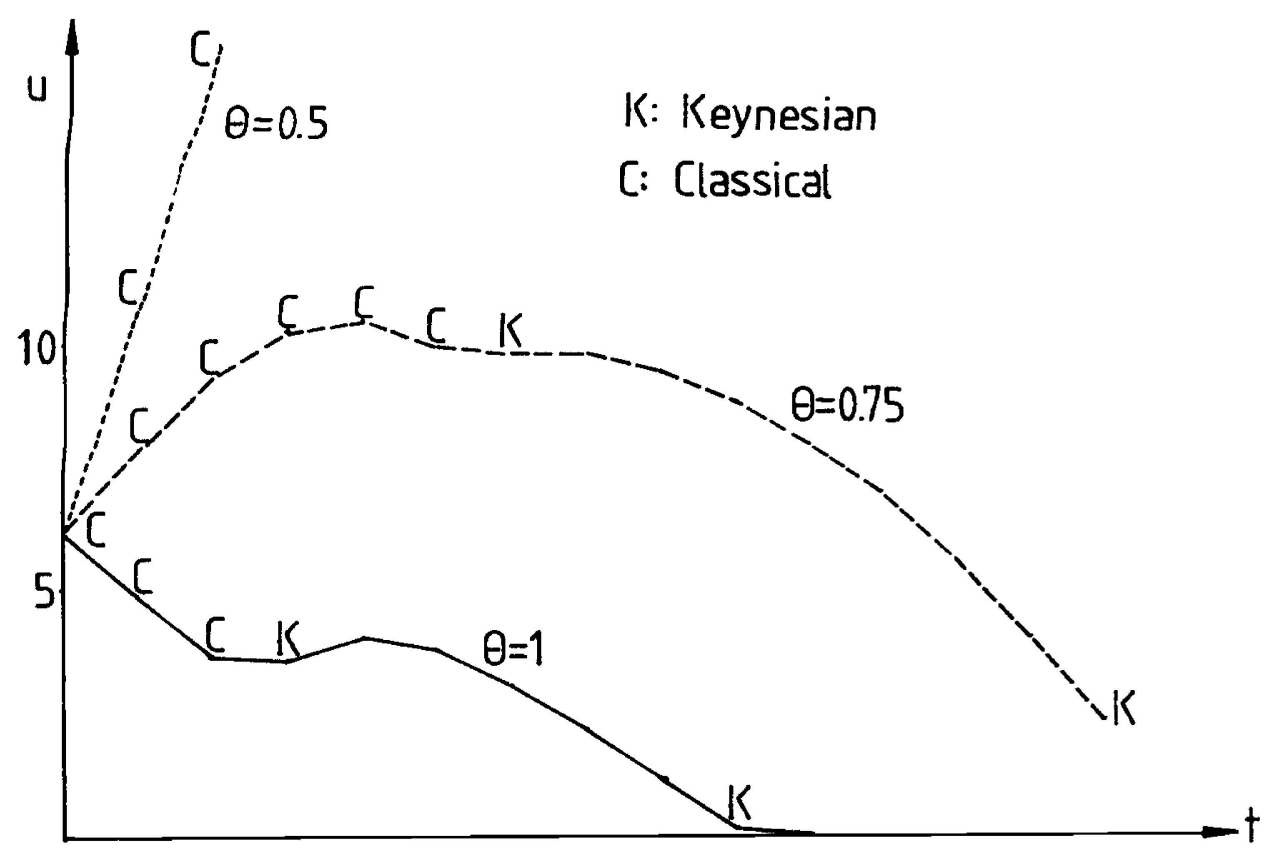

Fig. 2. Supply disturbance

2 This suggests that expansive monetary policy might work, especially in the "Keynesian " phase of the recession. This was tested by taking into account a "monetary rule "linking the supply of money to the lagged rate of unemployment. As expected, this had very little effect in the phase with classical unemployment, but it did reduce the Keynesian unemployment appearing later in the recession. 
From Figure 2 it is evident that any automatic increase in the payroll tax in response to the increased unemployment benefits, makes the recession much worse. In fact, when $\Theta=0.50$ or less, the payment system actually destabilizes the model. Even when $\Theta=.75$ the stagflationary effect of the supply shock is fortified to a considerable extent, causing in fact an even larger accumulated public deficit than in the case of $\theta=1$. Therefore, in the case of a supply shock, a "Laffer curve " effect seems even more likely than in the case of a demand disturbance.

Although one should never take numerical experiments of the kind reported here too seriously, the results are probably robust with respect to the different effects of demand and supply disturbances. In the former case, adjusting the pay-roll tax rate according to past payments of unemployment benefits may not hurt very much if appropriate stabilization policy measures are undertaken. In the latter case, however, any increase in the unit labor cost could have very serious consequences for employment.

\section{Appendix}

Our numerical experiments were based on the following parameter values:

$$
\begin{aligned}
& A=1.31951, \alpha=0.6, K_{v}=16, \bar{L}=1, \lambda=0.25, \delta=0.05, \quad \rho=0.05, \\
& \beta=0.9, \bar{M} \text { (money supply) }=5.6, G=0.8, \text { income tax rate }=0.25, \text { initial } \\
& \text { stock of government bonds }=0 .
\end{aligned}
$$

This yields the Walrasian stationary equilibrium prices: $P=1, W=2.4, r=0.05$, assuming a zero payroll tax rate. The corresponding quantities are $Y=4, C=2.4$, $I=0.8, \Omega_{o}=56$.

The dynamic price equation is

$$
P_{7}=P_{1,1}+0.2 \cdot(E D Y)_{t-1}-0.5(S P)_{t-1},
$$

where $E D Y$ is the effective excess demand for output and $S P$, which is the difference between the market price and sellers' shadow price, reflects the degree of excess supply of output. $E D Y$ and $S P$ are complementary variables, i.e. $(E D Y) \cdot(S P)=0$, and $E D Y \geqslant 0, S P \geqslant 0$. The chosen coefficients imply that price is more sensitive to excess demand than to excess supply.

The (real) wage equation is

$$
w_{1}=w_{i-1}+0.4(D W)_{1-1} / P_{i-1}-0.2 u_{t-1}+0.1 \cdot \pi_{i-1}
$$

where $D W$ is the difference between the buyers' shadow price of labor and the nominal wage rate, $u$ is the rate of unemployment (complementary to $D W$ ), and $\pi$ is a measure of profitability:

$$
\pi_{t}=Y_{1}-w_{i}^{\bullet} L_{t}-\left(r_{t}^{\bullet}+\delta\right) K_{t-1} .
$$

In stationary equilibrium, $\pi$ is of course zero. In (A.3), $w_{i}^{\bullet}$ and $r_{i}^{\bullet}$ are the expected future real wage and rate of interest respectively. These expectations are determined adaptively according to equation (8) in the main text. In all expectation formation equations in the model, $\gamma=0.5$. 
Perceived wealth $(\Omega)$ is defined as

$$
\Omega_{t}=\frac{M_{t-1}}{P_{t}}+\frac{(G B)_{t-1}}{P_{t}}+R_{t}+\frac{R_{t}^{\bullet}}{r_{i}^{\bullet}} .
$$

In (A4) $M_{t-1}$ and $G B_{t-1}$ are the stocks of money balances and government bonds at the end of period $t-1$, respectively, $R_{t}$ is real private (after-tax) income, $R_{t}^{\bullet}$ is the expected future flow of real private income from labor and capital, and $r_{i}^{\bullet}$ is the expected future rate of interest.

In the investment equation, the desired capital stock $\left(K^{\bullet}\right)$ is

$$
K_{i}^{\bullet}=\frac{1-\alpha}{\alpha} \cdot\left(\frac{w_{i}^{\bullet}(1+\tau)}{r_{i}^{\bullet}+\delta}\right)^{\alpha} \frac{Y_{i}^{P}}{A},
$$

where $\tau$ is the payroll tax rate. Planned output $\left(Y^{P}\right)$ is determined by

$$
Y_{t}^{P}=Y_{t-1}^{P}+(P S)_{t} \cdot\left(Y_{t}-Y_{t-1}^{P}\right)+3 \cdot(E D Y)_{t} \cdot \pi_{t} .
$$

In the case of excess demand for goods, it is assumed that private consumption and investment is reduced by the same quantity.

The calculation of unemployment benefits $\left(B_{t}\right)$ was based on a replacement ratio of 0.8 . In order to capture an income redistribution effect in a simple way, we added 20 per cent of the unemployment benefits to the demand for consumption in the same period.

With respect to the computation of short-run equilibria, the model is posed as a non-linear complementarity problem and then solved by a sequence of linear approximations, see Lensberg [1983] and Mathiesen [1982]. ${ }^{3}$

\section{REFERENCES}

LENSBERG, T. [1983] : “ A dual route to computable fix-price equilibria ". Discussion Paper 0583, Norwegian School of Economics and Business Administration.

MALINVAUD, E. [1977] : The theory of unemployment reconsidered. Basil Blackwell, Oxford.

MALINVAUD, E. [1980] : Profitability and unemployment. Cambridge University Press, Cambridge.

MATHIESEN, L. [1982]: "Complementarity and economic equilibrium. A modelling format and an algorithm ". Norwegian School of Economics and Business Administration.

3 The computer programme has been developed by Terje Lensberg and Tom Rutherford at the Center for Applied Research, The Norwegian School of Economics and Business Administration. 